\title{
Research on bidding strategy of construction project YangXin
}

\author{
Yunnan University of Finance and Economics, Kunming, China
}

\begin{abstract}
KEYWORDS:construction;bidding ;strategy;
ABSTRACT: At present, in promoting China's government, bidding has become the main method of project contract. In this situation, the bidding has become one of the most important business activities, In a market economy enterprises, only through the bid winning their own design, Labor or service "marketing"methods, in order to achieve the production task, profits and eventually make the enterprise survival and development. Bidding strategy is that bidders make the action guiding principle and behavior way according to the special details of the competition environment. It is the human's in competition environment guiding ideology.
\end{abstract}

\section{INTRODUCTION}

Bidding is bidding for engineering and to determine the contract the total cost of the project needs, this is the core problem of project bid.The so-called bidding strategy, refers to the contractor in the competitive bid to bid for the tender guiding ideology, system center construction work plans and to participate in the bidding competition mode and method. Its purpose is to solve to modeling problems, to guide the bidder in the complex multi-objective, multi-level game to impress the tenderer, outwit his opponents, most favourable conditions to obtain target, realize the maximization of their own interests.

In the research of the bidding strategy of construction project, there are a lot of ways and methods for the selection, even including a lot of high-tech achievements. However, in order to make the tender units to obtain the optimal effect, to maximize their interests, should choose the corresponding to the bidding documents in one of the most for the bidding strategies and effectiveness of the methods.More and more entrepreneurs begin to pay attention to their own bidding, bidding activities of thinking and summing up, some leading enterprises also embarked on the road of cooperation with colleges and universities.

This paper mainly studied the bidding activities, hoping to find the regularity with it and be used, the results of this study hope to help enterprises to improve scientific, bidding promotion bid winning ratio has the reference value.According to undertake a progressive sequence on the bidding strategy is studied systematically, the general idea is: firstly, introduces several main factors in the bidding strategy, bidding decision-making method and the effect of the bid decision. Analysis of bid decision quantification method, finally has carried on the bidding strategies for a specific project bidding process in the case, then the conclusion of the paper and suggestions.

\section{ANALYSIS OF BIDDING STRATEGY}

\section{The bidding strategies of classification}

(1)To obtain higher profit pricing strategy. Tender offer, it is necessary to consider the enterprise's own strengths and weaknesses, to analyze characteristics of bidding project. According to the project characteristics, category, different construction conditions to select bidding strategy. The so-called gain higher profit bidding strategy, is to choose high profit price bid. That is to say, in the face of the following situations can offer higher: poor construction condition of the project; the low value of small engineering project, and you do not want to do, it is not convenient to tender; special 
projects, such as ports, underground excavation engineering; construction period requirement urgent engineering; bidding on the hand less engineering; terms of payment not ideal engineering; technology intensive engineering high professional requirements, if the company has expertise in this area, the higher prestige can choose high profit price.

(2)Low price bidding strategy. Low price bidding strategy is the construction enterprise bidding under certain conditions and environment, a strategy and method to use, the price is a relative concept, "high" and "low" is an objective, less than the degree of price competition, malignant competition actually has damaged the market effect, but if the tendering units as he would like to be able to win the bid, the bidding unit is not good, at least can enhance the visibility. So some tender units with low price bidding strategy of course also has its inevitability and necessity. At the same time, a method of the low bid is the use in the bidding strategy, sometimes not malicious damage to the fair competition of the market.

(3)Unbalanced quotation. Unbalanced quotation is a project of the total price to determine the basic, through various projects Interior modulation price, can not increase the total price, does not affect the bid, and can get more ideal economic benefit in the settlement of action.

Except for a few kinds of bidding strategies and methods described above, there are many methods of bidding, the bidding decision actually, are facing the problem of complex, this is because the winning bidders to perform the actual cost, contract contract real quality are uncertain, the uncertainty of the index into the bid, the bid price is uncertain and imprecise. Therefore, to accurately and safely bidding a project, often need to use and balance of different strategies, in order to improve the winning probability.

\section{Analysis the influence factors of bidding dicision}

Enterprises want to choose the proper bidding project, we must first understand what the project in the tender, and collect and master the information and information about the project subject to tender, do tracking earlier. In today's information society, the choice of own favorable bidding project, to do pre tender preparation, strive for the winning bid is very important. Otherwise, to not understand tenders. To tender after seeing the ad, often because the time is urgent, rush into a passive, resulting in failure, lose the opportunity.

Enterprises should establish a comprehensive source of information channels. Our bidding is in under the guidance of the state plan, organize, lead. The relevant bid information source is very clear.Preparation of the bidding project list, the conditions of a project subject to tender in the table, and change with time and circumstances, to be supplemented and revised in time, it is very necessary for comparison, weigh, select favorable bidding project.

Table 1 The bidding project list

\begin{tabular}{l|l|l|l|l|l|l|l}
\hline \multirow{2}{*}{ Serial } & \multirow{2}{*}{$\begin{array}{l}\text { Project } \\
\text { name }\end{array}$} & Area & \multirow{2}{*}{ Time } & \multicolumn{3}{|c}{ Project type } & \multicolumn{2}{c}{ Construction } \\
\cline { 4 - 7 } & & & Sype & Scale & Funds & $\begin{array}{l}\text { Contents and } \\
\text { contion } \\
\text { characteristics }\end{array}$ \\
\hline
\end{tabular}




\section{QUANTITATIVE METHOD IN BID DECISION}

Investigation of the project subject to tender, We bid for the project itself to have a general understanding But the choice of which project bidding is the most favorable, is still a very difficult to estimate and to grasp the problem, there are many factors to consider. Here we only from the factors of profitability size analysis, select the desired value of the maximum profit from project, as the bidding project. Selection method using quantitative approach to decision making. Analysis of quantitative method or system, is an important aspect to improve the level of decision. It is to study the problems of management, expressed as a mathematical model, and then by calculation or simulation methods, optimization in under specified constraints, thus providing scientific, quantitative decision-making basis. This method is also widely used in the bidding.

\section{The method of linear programming}

Through the establishment of linear equation satisfy the constraint conditions, and draw the corresponding image, draw the feasible region, the maximum profit.To determine the ultimate solution. This needs according to their own ability, Weigh two engineering level of profitability, make the right bid scheme.

\section{Decision tree}

According to the decision of the probability distribution, there is a certain risk, so the risk decision. Decision tree is one of the best ways to solve the risk decision making. Decision tree is a tree branch growth process simulation, from the starting point began to branch to express various possibilities to analyze problems, and to maximize the expected value of the branch as the basis for the selection.

\section{CASE ANALYSIS}

This section aims to specific cases to illustrate how to use the method of concrete analysis and calculation.

\section{Project overview}

Project Name:

(1) a section of a highway project in the. Among them, the design speed of $120 \mathrm{~km} / \mathrm{h}$, two-way four lane design, all closed, the whole highway, roadbed width of 28 meters.

(2) the main quantities: the section of route length of $12.030 \mathrm{~km}$, total $2130830 \mathrm{~m}^{3}$ of subgrade, foundation stone processing $26100 \mathrm{~m}^{3}$, bridge $1165 \mathrm{~m} / 1$, mid-bridge $39 \mathrm{~m} / 1$, culverts 7 , channel 26 .

(3) duration: 32 months.

Given another five companies participated in the bidding for the project, but do not know which specific five companies. After calculation, the contractor that the project budget for the cost of 44217162 yuan (not including the profit and risk cost).

\section{Application of bidding strategies}

Analysis of the initial:

(1) the project owner: Highway Administration Bureau in accordance with the provisions of the province, specifically for the construction, the project management, registered Incorporated Company, have selected management experience of large-scale highway construction, style a few comrades decent served as the main leader of the item company. The investment by the traffic 
department of the province to raise, and has been included in the plan of capital construction. The project commissioned by the owners bidding agent bidding matters all normal, and there is no disadvantage of the administrative protection of the enterprise.

(2) Environment: this section is an important part of the highway main bone in south central artery, is an important link national trunk highway with three and the Beijing Shanghai expressway. The completion of the road, to accelerate the construction of the highway network, improve the external traffic conditions and the investment environment, the development of tourism, and promote the combination of things, to further implement the development strategy, give a great impetus to the development of economy; it has special significance to the prosperity of the economy and strengthening national defense. The local government and the masses is more support for the project construction, construction disturbance will occur in the process of construction, but it is not too serious, construction environment is better.

(3)Unit status before bidding: the bidding project prequalification notice published in "Chinese traffic report", was the Shanghai a limited ability to complete the project, and the construction task is insufficient, a large number of personnel and equipment will be idle, the bidder to construction contract to the new project, so that the idle resources use.

According to the judge criteria of $\mathrm{a}=1, \mathrm{c}=1 \mathrm{f}=\mathrm{g}=\mathrm{j}=$ null, in the above analysis, the criterion for the bidder did not pay special attention to, can think the conditions are not met, so were the null, the affirmative judgment are as follows.

$$
\begin{aligned}
\mathrm{V}=\mathrm{a} \times \max (\mathrm{b}, \mathrm{c}, \mathrm{d}, \mathrm{e}) \times \max (\mathrm{f}, \mathrm{g}, \mathrm{h}, \mathrm{i}, \mathrm{j}) \\
=1 \times \max (\text { null }, 1, \text { null, null }) \times \max (\text { null }, \ldots, \text { null }) \\
=1 \times 1 \times 1 \\
\quad=1
\end{aligned}
$$

So I decided to participate in the project bidding.

\section{CONCLUSION}

Bidding theory and strategy research is a very meaningful topic. For the contractor, study how to bid is a very urgent problem. Through the study of this problem, draw the following conclusion:

(1)To further improve the level of decision-making, need to analyze the quantitative method was used in bid decision, this paper gives the method of linear programming and decision tree, for bidders in bidding selection. At the same time, this paper points out that, in the bidding, the time value of money is the economic problem must notice.

(2)In bidding, price bidding strategy is the construction enterprises in the cruel market competition condition is an important means for survival, but this is not the only means.Construction enterprises have suffered in many of the low price competition of the setbacks and failures, largely because appeared this vicious competition low-cost disorderly situation.

Of course, it should be pointed out, any strategy may not be perfect in every respect. Bidding strategy can not guarantee that enterprises will be able to win the bid and win profit, cannot replace the decision-maker's experience, ability and judgment. But if the decision-makers to analyze objectively and prudently the industry competitive situation, capacity and operating conditions on their own knowledge, comprehensive use of various auxiliary tender bidding strategy, can improve the strength of the situation, make yourself in a favorable competitive position. 


\section{REFERENCE}

[1]. Harsanyi, J. Games with Incomplete Information Played by Bayesian Players[J]. Managament Science 1967-68, 14:486-502.

[2]. Kreps, D. Game Theory and Lconomic Modeling [M]. Oxford University Press 1990.

[3]. Nalebuff, B. J., A. M. Brmdenburger. Co-opetition[M]. New fork: Currency Doubieday, 1996.

[4]. Nash. Equilibritm Points in n-Person Games[J]. Proceedings of the National. Academy of Science, 1950. 36: 48-49.

[5]. Nash, J. Non-cooperative Games[J]. Annals of Mathematics, 1951, 54: 286-295.

[6]. Saloner, Game Theory alld Strategic Management: Contributions, Applications, and Limitation[J]. Fundamental issues in strategy. Harvard Business School Press. 1995.

[7]. Milgram, P., J, Roberts. Limit Pricing and Entry under Incomplete Information: An Equilibrium Analysis[J]. Econometrica, 1982, 50: 443-460.

[8]. McAfee, P. J. McMillarl. Competition and Game Theory[J]. Journal off'Marketing Research,Chicago, August. 1995, 33(3): 263-267. 